Notes on Idiocy.

By P. Martin Duncan, M.B. Lond., \&c., Essex Hall Asylum.

IT is remarkable, considering the advance which has been made in the study of the diseases of the mind during this century, that so little is still known concerning idiocy and idiots. With an increasing population, there is no decrease in the numbers of these helpless beings; their origin is connected with the, apparently, inevitable results of our social system; their very existence is, in most instances, a natural protest against vexatious and unreasonable interference with those great laws which govern the well-being of communities; and, both in a scientific sense as well as in a philanthropical, they have great claims for consideration.

Yet the literature of idiocy is scanty.

It consists of one admirable volume by Seguin, many reports of American origin, by Dr. Howe, of English, by the projectors of idiot asylums, and of pamphlets and speeches.

The few valuable pages on idiocy, left by the great alienist physicians of the early part of this century, and the work by Seguin, constitute, however, the foundation of nearly all these last; but the medical attendants of our large asylums have, of late, had the opportunity of bringing forward many reliable facts, and of correcting many errors, in connection with their speciality.

Seguin has been unmercifully quoted, or rather his able pages have been plagiarized, by those who have commenced the practice of the education of idiots with pamphlets, explanatory of what they intended to do; but experience, the result of a year or two devoted to the question, determines that this standard work is too theoretical, and that it has been based upon the very careful study of but a comparatively few cases.

In fact, as regards idiocy, science has been left behind by charity, and philanthropists, rather than philosophers, have offered instruction; the platform has taken the place of the quiet study, and well-intended exaggerations and very exciting but equally baseless statements, have influenced the public mind, rather than carefully collected facts and logical inductions.

To prove the correctness of these assertions, it is simply requisite to turn to our text-books on insanity and to read in the public journals, speeches made for the benefit of some noble charities within the last ten years.

Much good, however, has arisen from the efforts of the founders of Earlswood and Essex Hall, and, as years roll on, the subject will be divested of much that rather reflects upon it, and will take its place amongst those worthy of scientific study. 
As yet, it has not received great attention from any one who has had the advantage of that education which qualifies the alienist physician for his career, and theory has put practice to the blush.

The principal efforts of the few writers on the theory of idiocy, have been directed to the relation between the size of the head, or of certain parts of it, and the amount of mental deficiency; in fact, phrenology has been put on its trial by those who had a leaning towards its dogmas : others have referred to the definition of the word, and of those terms which are used in the classification of the feebleminded, and to the classification itself also. .

In America, the causes and statistics of idiocy have received attention, but only enough to prove that much greater research is requisite before a satisfactory conclusion can be attempted; and in the Old World as well as the New, a few post-mortem examinations, a few measurements of the head, and a few cases of idiocy, have been from time to time published.

This state of things is not surprising, for the subject is distasteful ; idiots are rarely of any legal importance, and therefore their cause is not often before the public, and their parents, as a rule, will do anything rather than let it be known that they are even in being. There are few incentives to the study ; success in the educational department requires patience, knowledge, tact, and experience; and the commercial considerations which more or less influence men, are not of importance: there is not much dross hanging to their skirts. Their study had been almost impossible, to even a few, until the formation of the large asylums in Europe and America ; and even now, experience and knowledge are attained with difficulty.

There are many of the same difficulties to be overcome, which are met with, in the study of insanity, and it is evident that a knowledge of medicine and of the accessory sciences is requisite.

It may readily be imagined, from the paucity of reliable and trustworthy information on idiocy, that hasty generalizations, baseless assertions, and captivating theories should abound; nor is it likely to be doubted that the first steps of the truthful inquirer, when brought into contact with the objects of his study, are retrogressive. To unlearn is to take a great step in this, as in many other pursuits.

Bright hopes of success, the product of excited sympathy, fade away ; preconceived notions concerning the relation of the expression of the face and the form of the head, to the amount of mental deficiency turn out to be fallacious guides in diagnosis; ideas about the effects of arrested nervous development become less definite, and the value of the best classification diminishes before the test of practical experience. It may be safely asserted, that any one determined to study the subject of idiocy in a manner consistent with the rules of science, and not merely with a view of sinking into the successful teacher of the feeble-minded, has much to unlearn at the commence- 
ment of his researches ; and also that any one possessing the opportunities offered by an asylum, abundance of cases, occasional post-mortem examinations, and the command of all the appliances supposed to be requisite for the training of the patients, will own, after a few months' labour, that the subject is bewildering from its complications and extent. Facts are collected carefully, and reasonable theories are induced from them, to hold ground, however, but for a while-until one or two recent cases completely set them aside. Of course, this is a necessary condition in the progress of all scientific inquiry, and is most frequent in its early stages. Much time is, of course, lost in classifying the grades of idiocy, in determining the definition of terms, and even in identifying the proper objects for study.

There are numerous varieties of idiots, to whom the appellation is not applicable ; others have been given, and must be considered; and moreover, every inmate of an idiot asylum is not, of necessity, idiotic.

The complications of the subject are principally the result of the general ignorance of the public; charity does not infer wisdom, and sympathy, as a rule, discriminates badly. To all intents and purposes, the public idea of idiocy and of the proper inmates of idiot asylums, refers to all those who cannot be educated by the ordinary methods of schools - who are unusually stupid, dull, perverse, and obstinate, and who cannot be rendered cleanly and proper in their habits. Age and the presence of evident disease of the brain, and even the knowledge of mania having occurred, do not enter into consideration. The object is a good one, and care is taken to shut the door upon no one. Our profession, influenced by the same charitable feelings that prompt the public, and not well informed upon idiocy, gives its sanction to the admission of cases into idiot asylums which are certainly objects of charity, but not idiots. Certificates of lunacy are written, and extraordinary reasons for considering the subject a fit case for an asylum, are often given.

At the commencement then, there arises a complication; a rough classification must be made, to be generally altered hereafter, and a great number of so-called idiots, have to be separated and distinguished from the rest.

It becomes manifest that, besides those considered the proper objects of study, there are found in asylums-1. Children who have been badly treated and taught, during early childhood, in whom an artificial hebetude is rendered most difficult of eradication, by the presence of constitutional irritability and a physical ailment or deformity. 2. Children born with ordinary intelligence, and who have been exposed to excessive fright, to direct injury, or who have had some brain-disease during dentition. 3. Those in whom epilepsy and mental dulness and inertia have been induced by solitary vice. 4. Those who have attained the age of puberty with perfect intelligence, yet have been brought down to the level of the idiot by the 
results of active disease the brain, typhus, or concusilon. 5. Cases of dementia. 6. Sufferers from the advanced stage of the general paralysis of the insane.

All these are, of course, as helpless and as much in want of careful supervision as many idiots, but they are not the immediate objects of our study. The consideration of their mental and physical peculiarities, morbid anatomy, and previous history, must fall more or less under notice, for it affords many links in the chain of explanation when the difficulties of the investigation of the phenomena of true idiocy are encountered.

Those of the first class are termed "backward children :" the empirical method of schools will not bring them forward; but a judicious training, akin to that adopted in idiocy, soon develops mental powers never possessed by those for whom they are mistaken. Their progress determines the propriety of their separation from the idiot class; but it happens that these cases are not separated as much as is possible, and thus the wonderful (?) result of education is paraded to advantage. The diagnosis is, however, excessively difficult, and will be considered in a future page.

The members of the second class, afford many of the mental peculiarities of idiots; they possess often great personal attractions, but their epilepsy or other evidence of chronic affection of the brain, renders many symptoms apparent which are not found in the idiot. Many of them, as age progresses, become insane, or evince a maniacal fury before or after their periodical seizures. The reason for their separation is as evident as is that of all the other classes.

When this classification is complete, and these "accessory cases" are separated, the congenitally deficient in mind and aberrant in physical form and function, the idiots, stand forth more clearly.

Not to be mistaken in the most aggravated forms, distinguished with difficulty when slightly endowed, from some of the "accessory forms," they merge gradually, as intelligence and physical power increase, into the condition of those who may be considered as repre- senting the lowest types of normal human capacity.

When free from the complications caused by charity, those peculiar to the subject commence, and that hinted at, in the last sentence, is not easily overcome. The approximation of idiots to the dull and stupid amongst our lowest types, infers that the term idiot (solitarius) is not very specific, and that its possible application may be questioned in many cases. It may be imagined that there are some narrow and distinctive lines of demarcation between the two, such as a physical defect, an abnormal shape of head, an inability to utter perfectly, or the impossibility of the comprehension of an abstract idea; such is not the case. There is, as far as my observation goes, a constant difference : it is of no great value in some cases, but it will receive attention in the course of these pages. There is then at the onset, a diff- 
culty in diagnosis, which increases when the lowest types of different social classes are placed in contact with a presumed "idiot" of high class.

It is admitted that social position and external physical influences, have a great effect upon determining the various intellectual standards. The intellectual standard of a plough-boy in a remote district, where want, ignorance, dirt, and mental inertia are ever acting upon the results of intermarriage, is infinitely below that of the city Arab or the young sailor. It is superior in many cases to that of its corresponding social state, in other countries.

The dulness and mental inertness of the peasants of Spain, Poland, and Russia, is greater than that of ours; their intellectual standard is lower; and, singularly enough, the lowest types of those debased people, approximate more distinctly to the highest amongst their "simpletons" than do the lowest types of our most ignorant peasantry.

There is a difference between the evidences of idiocy, in different social classes, and in the same social classes in various countries, and the highest idiots of a nation like ours, are higher than those of a nation with a lower standard of intelligence; they are moreover less vicious and brutal than those of the countries where violence, ignorance, vice, and drunkenness are more open to the public gare than they are with us.

When the idiot of this higher class has been educated, he will often hold his own with those who are outside, and who are considered perfect in mind. But, as a rule, the inability to contend with those troubles of this world, which are particularly felt by the social class to which they belong, will ever render the educated idiots objects of attention and of derision by those of their years. An adult blessed with fortune, and its kind friends and admirers, may be merely a high idiot who has been carefully trained. He may pass muster, may dress in black and hold his tongue, and may deceive multitudes; but the same individual shorn of his externals, and lowered to a class dependent upon labour and skill for its bread, would speedily find his level. The consideration of class and of age must, therefore, enter into the first thoughts of our subject, as these naturally relate to the classification of the idiots, after the separation of the "accessory" cases.

The terms used in the literature of idiocy, complicate the first steps of practical inquiry greatly, and different writers, regardless of the necessity for unanimity, use the same words to identify various classes of idiots. It soon becomes manifest, that a total revision is necessary, and that when the subject has been studied for years, and its theoretical portion becomes advanced, the word "idiot" itself will have to give place to some other, more expressive of the cases to which it is now applied. A very small per-centage of those termed idiots, even after the accessory cases are separated, really merit the appellation. To be solitaries, special sense and the lowest instincts must be 
denied in a great measure; yet the various grades of the feeble-minded, up to those emerging into the lowest types amongst the normalminded, are thus called.

Many have used "idiot" as the generic term, and have employed as specific, the words fool, imbecile, and simpleton; others consider the word idiot in its proper sense, and restrict its employment to those cases which are really solitary, the term remaining with its generic value still.

The term imbecile, which is of course applicable to all the feebleminded, is restricted by some to the highest class of idiots, by others to the intermediate class, and is only applied properiy to those cases which have been born with normal intelligence, but which have been rendered feeble in mind by subsequent disease of the brain-the members of the second class of accessory cases.

The word fool is applied, by Howe, to the class just above the true solitaries; but why append a word of reproach, when a number will do as well as a term?

Simpletons, to my mind, are the highest class of so-called idiots, yet the term has been used quite as extensively as that of imbecile.

Upon examining into the definitions of these terms, they will all be found wanting; and it will appear, from the reports of cases, that idiocy is capable of practical definition in a negative sense, but that it is no more to be positively defined than insanity.

The necessity for a new classification, and for new terms, becomes more evident, as idiocy is gradually found to be quite as much a physical as a psychological state of constitution, and as the vices in conformation of other structures, besides those of the nervous centres and nerves, are recognised; but before this can be accomplished, much more than is at present known, concerning the questions which affect the extent of the subject of idiocy, must have been attained.

The statistics of idiocy have not received much attention, and those relating to the causes of this abnormal condition, have not produced any satisfactory conclusions. It would appear that the statistics of one nation will not apply to the idiots of another, unless the social and climatic conditions are the same; and this is clearly seen from the results of the Massachusetts report (1848). This report, which would form a good model, for one which ought to be set on foot by our own government, applies to an energetic, rude, hard-working race, fighting earnestly against external circumstances, and whose vices are very positive. But many of its fairest conclusions begome doubtful, when they are examined and tested by our experience amongst our own countrymen, whose social condition is different, whose difficulties, as a rule, are not nature's, and whose vices are more secret and less prominent. In America there is hardly a case whose history does not bear upon its cause; here it is quite the opposite.

The causes of idiocy have received great attention, but, as yet, not 
on a large scale; they are, of course, most worthy of scientific research, for the questions embraced are of the greatest social importance, and relate to many of the great moral and physiological questions of the day. Unfortunately, they have been investigated, before a practical knowledge of the varieties of idiocy has been learned, and those referring to cretinism, have been mixed up with those relating to idiocy and the accessory classes, already referred to. There is, of course, no universal cause, but all ultimate causes are variations of all that tends to diminish the physical strength and vital force of a series of individuals brought into contact by social causes. The proximate are usually referred to the nervous system; formerly, they were considered purely psychological, but Seguin first asserted that idiocy was quite as much a disease of the nervous centres and their expansions, as a deficiency of mental attributes. In my opinion, the phenomena, physical and psychological, of idiocy, are not immediately caused by an incomprehensible and immaterial psychical force, or by some physical abnormity of the nervous system alone, but by a generally abnormal condition of the osseous and muscular tissues and organs also. It is impossible to explain many of the physiological peculiarities of idiots by simple reference to the nervous system. But the place for these considerations is, evidently, after the determination of the varities of the condition.

The pathology of idiocy is more interesting and perplexing than instructive, at present. The morbid appearances, usually published, are, as a rule, divested of any history relating to the physical and mental peculiarities of the case, and refer generally to the size of the head, and the alteration in the brain and its membranes; to anomalies of structure, deficiencies of parts, and to presumed arrested developments. It is evident that the present knowledge of the general configuration, minute structure, and physiology of the nervous system, great as it is, is not sufficiently exact, to enable us to discover the relation between alteration in the minute structure and evident perversions of function. The functions of the parts of the brain and cord are not yet satisfactorily known, and their minute anatomy is far from being determined upon. There are only general ideas concerning the functions of the commissures, and yet their respective duties must have great bearings upon our subject : the minute anatomy of the cord is in the most complete state of transition from error to truth, yet the principal peculiarities of idiots relate to that organ. There are no two inquirers on the Continent, who are agreed upon the most important microscopic appearances of the parts of the cord and medulla oblongata, and my friend, Lockart Clarke, has the advantage of differing from them all. There are no illustrations of the development of the convolutions, from the middle foetal months to the time when the brain is presumed to cease growing, and even this time is not fixed. Nevertheless, want of development and arrest of development, are 
household terms in idiocy. Take a fact. One idiot child, just above a baby of a week old, in mind and power, yet five years of age, has a head of the usual size of that age, and a placid, vacant face. Another, of the same age, has a broad base to its skull, and the rest shaped like the top of a hayrick, shelving to a narrow vertex, with hardly any lateral regions : its forehead is low, and the face resembles that of a foetus; and it stands and walks a little. The first died with the same powers as it had at birth ; the second learned to stand and to move, and to shake hands feebly, -no more. The first had a goodsized brain, with the convolutions of a child; the second, a brain in the shape of that of a fox, with flattened convolutions. Reconcile this, if possible, with our present knowledge.

The anomalies presented by idiocy, constitute one of its few charms; their constant occurrence stimulates the desire for exact information; and if an anomaly be merely an unconnected link in the great chain of evidence, its study will, of necessity, repay. To be successful, then, it is clearly necessary to have a knowledge of the minute anatomy of the cord and brain,* both of the healthy adult, as well as of that of the foetus in the last months, and of several ages of childhood. Moreover, the laws of fœal deformity (teratology), as described by St. Hilaire, and amplified by Vrolik, $\uparrow$ should be studied, if the pathology of congenital idiots is to be understood, and, in addition, the physiology of infantile life.

The large asylums must illustrate the pathology of idiocy in the course of years, but at present, any descriptions relating to the psychology of the cases are most rare. There are, at present, the well-known recitals of the morbid anatomy of idiots before the profession, which include the so-called arrested states of development of the convolutions, absences of the eminences in the lateral ventricles, to deficient commissures and nerves; diminished consistence, increased consistence, and the same condition of brain as regards its bulk; increase and decrease of fluid; unsymmetrical conditions of the sides and parts of the brain, and abnormities of the membranes; thin skulls, thick and hard, and thick and soft skulls ; want of diploë, the whole skull being like a spongy bone; spiculæ and growths projecting inwards, and extraordinary development of the eminences which fit in, between the convolutions.

The symptoms, treatment, and prognosis of idiocy are better understood than any other portion of the subject, and are gradually being divested of empiricism : the predominance of certain mental gifts over all the others, the absence of some of the intellectual powers, and the dulness of all, are not now considered alone. The constitutional symptoms, the functional perversions and debilities, and the nervous

* Lockart Clarke's plan of manipulation, in the 'Trans. of the Royal Society;' is not difficult, and gives most distinct results.

+ 'Cyclop. Anat. and Phys.,' art. "Teratology."

VOL. VII. 
anomalies, are now considered of primary importance, and the condition of the digestive and circulating systems, the presence of hyperæsthesia of parts of the surface, of wandering vision, of automatic movements, and of deficient muscular co-ordination, are placed before the psychological symptoms in importance.

But, of course, the value of these physical symptoms, is determined by their relation to certain psychological peculiarities.

These last are difficult to discover; but, fortunately, the study of the diseases of the mind, has habituated those who are likely to inquire into idiocy to mental analysis, and, as medici and men of the world, the treatment, remedial and educational, ought to have a good basis amongst us. There is-to conclude these general observations-a study of quite as great an importance as any other, which must be sedulously followed, before any success can be ensured either in the observation or treatment of idiocy - the study of self.

A great cause of failure, in the investigation of idiocy, depends upon the mental and physical inaptitude of the stadent himself for his peculiar work. It is a peculiar work, and the pompous, the melancholic, the sulky, and the silent are not fitted for it. Their time is wasted.

Experience proves that the majority of attendants gradually prove useless, whilst a few possess extraordinary powers over their charges. Some can ever obtain attention and obedience, and the manner and address of these must be imitated. Frankness, open and plain speaking, and perfect kindness under all circumstances, are necessary ; and by avoiding any reference to self, and by carefully abstaining from evincing any knowledge of their mental defects and physical ailments, much more can be got out of idiots than might be anticipated. Those who are used to children, generally gain the confidence of the idiot, and the affection and gratitude evinced, is a repayment for much anxiety and disgusting toil. To show the necessity of this consideration, it is simply necessary to declare, that cases have been admitted into Essex Hall, on the certificate of medical men, who imitate Abernethy and keep up the dignity of their profession, as low idiots, who were then able to dress themselves, cut up their food, to speak slowly, and to understand a good deal! They would not answer questions.

Surrounded thus by many difficulties, idiocy still offers many incentives to study. It offers many propositions in physiology for solution, and quite as many in psychology ; its treatment is worthy of the physician, and its moral management brings forward many of the vexed social questions of the day. It is a pleasing duty to contribute to the happiness of one's fellow-creatures, and equally so to enable the idiot to enjoy a little life, and in some cases to accept the faith in our common Redeemer with a simplicity some of us may envy; but it is a moral obligation to place the cause of the idiot in its right light, to separate it from false impressions, and it is equally an obli- 
gation to propound the necessity of a rational education for all classes of the feeble-minded.

\begin{tabular}{|c|c|c|}
\hline \multicolumn{3}{|c|}{ CLASSIFICATION. } \\
\hline IDIOTS. & $\begin{array}{l}\text { Affection, congenital and } \\
\text { physical, as well as psy- } \\
\text { chological. } \\
\text { Suffering from various } \\
\text { functional disturbances; } \\
\text { from perversions of special } \\
\text { and common sensation; } \\
\text { from paralysis of sets of } \\
\text { muscles; from greater or } \\
\text { less irritability of the or- } \\
\text { ganic muscular system; } \\
\text { from inability to co-ordi- } \\
\text { nate many more orless com- } \\
\text { plicated muscular move- } \\
\text { ments to a common end; } \\
\text { locomotion defective in } \\
\text { ease and grace; voice very } \\
\text { rarely perfect; memory, in- } \\
\text { tellectual perception, fore- } \\
\text { sight, and power of abstract } \\
\text { thought, wanting in some, } \\
\text { and very defective in all; } \\
\text { automatic movements com- } \\
\text { mon. }\end{array}$ & 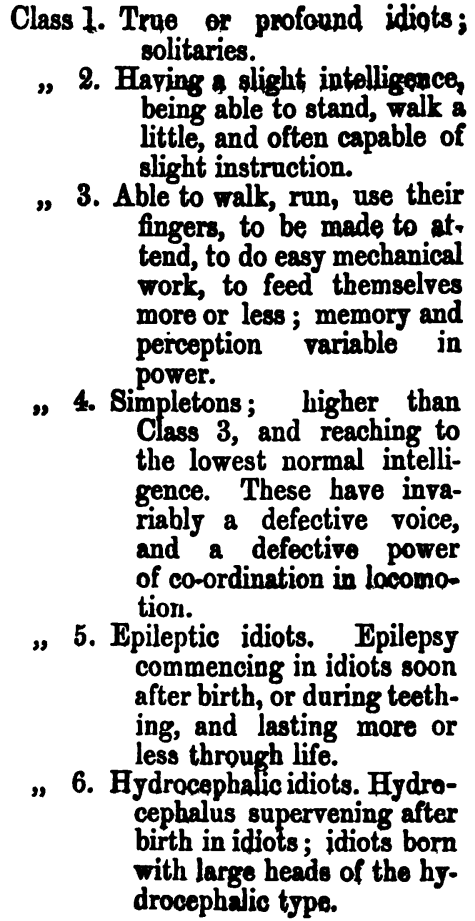 \\
\hline \multicolumn{3}{|c|}{ ACCESSORY CASES. } \\
\hline 1. IurbeciL & $\begin{array}{c}\text { Born } \\
\text { physi } \\
\text { sesse } \\
\text { induc } \\
\text { tric } \\
\text { lepsy } \\
\text { termi }\end{array}$ & $\begin{array}{l}\text { with perfect intelligence, and with the } \\
\text { isual attributes of infancy and child- } \\
\text { lood (not congenital). } \\
\text { itate of mind, but not necessarily of } \\
\text { sal peculiarity, like unto that poss } \\
\text { l by anj of the above classes has been } \\
\text { ed by fright, cerebral disease of eccen- } \\
\text { direct origin, or by injury. Epi- } \\
\text { is frequent, and insanity also a common } \\
\text { antion. }\end{array}$ \\
\hline $\begin{array}{l}\text { 2. CABIAB } \\
\text { 3. EPILET }\end{array}$ & 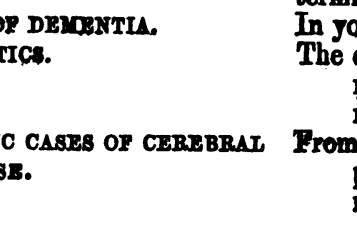 & 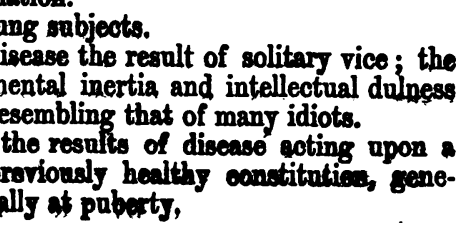 \\
\hline
\end{tabular}


These differ from the imbeciles in the prominence of the brain symptoms, and their invariably fatal termination in the course of a year or two, or less.

5. Cabes of the general para- In the stage of depression. IYSIS OF THE INSANE.

6. Cases of patuity in old $\triangle G E$.

7. BACKW $\triangle$ RD CHULDREN.

Badly treated, neglected, healthy children, constitutionally slow, dull, and obstinate, but educatable into useful members of society, or into the lowest types

Creturisz. of normal intelligence.

Allied to idiocy, but not coming under practical observation in English asylums.

(From my own impressions, it is a form of idiocy where the physical symptoms have the greatest prominence. The range of the cretin mind is the same as that of the idiot class. A sentence in a former page will give an idea why the idiots of some countries are more debased than those of others.)

It must be kept in mind, that there are no accurately distinctive symptoms which separate, clearly, the classes of congenital idiocy; there is a gradual progression in intellect and physical power from the lowest to the highest; yet the artificial and broad definitions submitted, will be found useful.

Age has its results upon the members of the various classes; some, without any educational efforts, emerge-thanks to the reparative power of nature-from the first into the second, and from the second into the third classes. The older a child, the higher should its class of idiocy be. Long and careful training raises many from one class to the other ; and the duration of educational means must be considered, with age and the amount of the domestic comforts given, before the probability of a greater rise is asserted.

Each of these classes presents its connecting links, in cases which resemble, in their peculiarities, those of the classes above and below, and the whole of those possibly embraced by them, may be compared with normal children. It is a very striking method of showing the mental deficiency of a member of any one of these classes, by comparing its mental gifts, with those of children of normal mind at younger ages. Thus, a boy of the fourth class, aged eighteen, may not have greater mental power than a healthy child of four years; ho is, to all intents and purposes, four years old, and dull for his age. An idiot of the second class, of eight years of age, may not be more than eighteen months in age, when compared with normal children, and the gaiety and spontaneousness are wanting.

Class I. True idiots.-Profound idiots-solitaries-are rare; and the rarity is increased by their mortality during early infancy, and 
between the first and second dentition, as well as by the fact that those surviving that period, frequently emerge into the second class of idiots. Constitutionally weak, they succumb to the usual infantile ailments; the irritation of the second teething is borne with difficulty, and those surviving must either have more than usual strength or unusual comforts.

Profound idiots live to adult age, and there are examples of menbabies who are as solitary as when they were born, and quite as helpless.

The growth is slow and imperfect, and disease has a terrible importance, trivial complaints frequently ending fatally.

There is no symptomatic form of head, face, or body, and in this class, as in all others of idiocy, those with ill-formed skulls and ugly faces are not lower in mental and physical power than others with well-formed crania and regular features.

Nevertheless, the profound idiot can be usually, not always, distinguished, at once, from any other. The face is without expression; the saliva often runs in quantity from the large open mouth, with its irregular teeth, high palate, and large lips, and the nasal mucus assists to render the face disgusting. The nose is often well formed, but its function, like that of the tongue, is not apparently distinctive. The eyes may, or may not, squint, their vision may be very slight, and they may be now fixed, staringly, on vacancy, and now wandering vacantly and without speculation; there is no light in them, no merry twinkle, and the head moves often from side to side, the vision being fixed by the minute together.

There is no visual perception in the lowest of the profound, and it exists in a slight degree only, in those which emerge into the second class. There is no ability to recognise one person from another, by sight alone. Short-sightedness is very common, and sluggishness of the irides also. The conjunctiva and cormea are often so insensible, and the reflex gifts of the eyelid are so sluggish, that the finger may be steadily poked right into the eye, on to the cornea, without winking being produced. The eye cannot be moved, by will, in the direction of an object, and bright light will often prove no incentive to cease staring or to attend. The ears are often misformed, and the power of hearing exists generally, but not the capacity of listening.

Voice is limited to screaming and howling, and sometimes one or two parrot-like syllables, are uttered.

In many, the process of mastication is impossible, and deglutition is very difficult.

The position of the head and trunk is either crouching or reclining; the forehead usually is dropped, but often queerly elevated, the face being at the same time moved obliquely. The neck seems too weak for the head; the trunk and limbs are not in correspondence, as regards power. Curvature of the spine, pigeon-breasts, bowing 
of the limbs, enlarged joints, contracted extremities, club feet, and shortening of limbs, with irregularities in the namber of fingers and toes, are more or less common.

The muscular development is bad; the co-ordination of muscles.in their movements is very deficient, and choreic movements are usual. There is either very little muscular power or great irritability, and this remark applies to the involuntary muscular system. The bladder and rectum are either unable to retain their contents, or else the contrary state occurs.

They cannot feed themselves; there is no idea of foresight, or of seeking food. The erect posture is impossible to the majority, and a few stumble about and crawl. Torpidity and indisposition to change posture are as frequently seen as the reverse. The legs and hands cannot be used for any necessary purpose. The heart is irritable, the pulse often very slow or intermittent, or unusually quick; the breathing is, in some cases, spasmodic, but in the majority it is as usual; the digestion is weak, and the urine and frces stinking. The skin is generally very dull in its sense of feeling, and parts of its surface are now and then exquisitely sensitive; the perspiration, as a rule, is fetid, and the temperature is low.

Thirst is usual, and voracious hunger as well. Sleep is usually deep, but in some cases very much the reverse. Habits of all kinds and tricks innumerable exist; moreover, the see-saw movements of the body and head, the side-to-side movements of the head, and the waving of the fingers before the eyes, are very common, and these movements are not dependent on the will, but are automatic.

There is, in some, no memory, in others the barest trace; appreciation of kindness and expectation of routine attention appear to be their highest gifts, and these are manifested in a very slight manner.

Pain is shown by unreasonable cries, and pleasure, in some few, by a vacant smile.

Low as the least gifted of these profound idiots are, and regetative as is their existence, still they afford plenty of evidence, when observed day after day, that there is cerebral, spinal, and excitomotor action, besides that of organic life. They are never deprived of all special sense, however low and scant it may be. Common cutaneous sensibility exists in various degrees; reflex movements can be excited, in some very vigorously, and in others very slightly. A certain amount of volitional action over muscles is seen in all. There are periods of sleep and of wakefulness.

From these symptoms of the varieties of the profound idiots, it will be observed that the excessive deficiency recorded by some writers is not thought consistent with fact. To find out the small gifts, time and quiet study are requisite, and without their aid, 
erroneous ideas will assuredly arise conceming the debasement of these inert and profoundly idiotic beings.

Grant to the highest of these all the gifts ever seen in one of its class, and compare them with the attributes of a child of the same age, and what a difference results!

There is a favorite notion, and a most unreasonable one, that those idiots present the mental and physical attributes of earliest infancy, that they never grow out of this state, and that "development is arrested." They have rarely the activity and volition of a babe, often not its endowment of special sense, and are very inert; they improve a little as growth progresses, and the profound idiot baby is more a baby than the profound idiot child.

The following cases, 1, 2, 3, refer to various types of profound idiocy, and they have been selected from cases watched for a long period :

CASE 1.-J. A. H-, male, æt. 6 years, admitted July 11, 1859. A pale, well-formed idiot of the lowest class.

Head. - Well formed, circumference $19 \frac{1}{2}$ inches. From mastoid to mastoid 14t inches; from nasal spine to occipital protuberance $13 \frac{1}{2}$ inches; long diameter 61 inches, short 4s inches. Its general configuration is symmetrical; it is high, but the frontal development is very good. Capacity for brain $44 \cdot 25$.

Face.-Pale, with no expression, no sign of intelligence; and when pleased by nursing, a wan smile is all the result. Eyes well made, but the power of vision is very slight. He stares fixedly, and will not follow the hand when it is waved before the eyes. At times the eyes wander from one object to another in an unmeaning manner, or they remain fixed upon space, whilst the head is slowly moved from side to side. Ears well made (externally). He hears, but does not listen. Nose well formed, and the sense of smell exists; his taste is very slight, and he can barely distinguish between nice and nasty things. The saliva runs from the mouth, which is usually open. Upper lip is large, teeth irregular and bad; the arch of the palate is high.

Voice.-None; no power of humming; he rarely cries or shrieks.

Body.-Well made, small, however, and weak in its muscular development. Lungs healthy. Heart very feeble in its impulse, and pulsations slow. The erect posture soon induces syncope. Abdomen rather hard. Bowels usually very constipated; bladder very sluggish also.

Arms.-Thin, well formed; the hands also. He can move them to grasp, at will, but not in an easy and perfect manner. They are generally in motion, being waved in the air before the face.

Legs.- Thin; the left hip is out of place. He cannot stand, nor sit upright. He can kick about, and roll over, but the usual posture is on the back with the legs drawn up. 
Intellectual powers.-None; does not recognise his own mother. Has no intelligence. Emotions barely exist; even passion is rare. The habits are those of earliest infancy.

General peculiarities.-He has to be treated like an infant. Does not suck, but takes food badly from a spoon; does not masticate. He has thirst, and drinks badly. He sleeps well. Perspiration not offensive; urine scanty ; tongue clean; reflex movements dull.

History.-Congenital; the idiocy noticed decidedly at the teething age. He has been well cared for, but no attempt has been made to assist the general vigour, or to awaken intelligence. Father and mother healthy, and there is no evidence relating to a cause of idiocy.

Cuss 2.-A. L-, female, æet. 6 years, admitted July 14, 1859. A thin, small-headed idiot of the lowest class.

Head.-Larger at the base than elsewhere; circumference $17 \frac{1}{8}$ inches; mastoid process to mastoid process $11 \frac{1}{2}$ inches; nasal spine to occipital protuberance 104 inches; long diameter 6 inches, short diameter 5 inches. Frontal development very small. Capacity $38 \cdot 75$.

Face.-Small and pale. When quiet, there is nothing idiotic about the expression; but when, as is usually the case, she is restless, the mouth is widely open, and the hand is stuffed into it, the expression is peculiar and silly. But, considering her age, the immobility of the muscles of expression is at its lowest ebb. Eyes large, vision imperfect. She looks about in a vacant, listless manner, stares fixedly for a long time, and possesses barely any power of fixing the eyes to examine an object. Ears large; she hears, but does not care for music, and does not listen. Nose well made; the sense of smell is evidently perverted. Mouth very large, lips large, teeth irregular, tongue large; the saliva runs in quantity from the mouth, and the nasal mucus from the nose.

Voice.-She can enunciate two unmeaning sounds. She screams loudly, and cries bitterly; rarely laughs.

Body.-Small and thin; chest deep; shoulders high, so that the ears nearly touch them. Pulse 60, small.

Arms and legs.-Thin. She can hold anything if she wills it, but not if it be placed in her hand against her inclination.

She can sit up of her own accord, lie down, turn round, stand in a curious stooping posture. She cannot walk slowly and in a straight direction, but sets off, one shoulder first, and, like a tipsy man, takes a staggering run to the left, then to the right, and so on. She usually brings her elbow close to the side, elevates the wrists, and allows the back of the head to drop forwards in running. The whole proceeding gives her the air of a rat. She cannot use her hands to any useful purpose. Automatic movements of the body, see-saw of the head from side to side, and of the hands before the 
eyes, are frequent. Constantly in motion; when not erect, she twists her body, and agitates her arms.

Intellectual powers.-None; does not recognise those who are kind to her. Does not care about her food. Cannot be made to listen or to attend. Emotions :- that of sorrow easily excited; she will scream by the hour, with wide mouth and open throat.

General peculiarities.-Everything placed in the hand goes to the mouth, without discrimination. She has attacks of spasmodic asthma. The scalp is tender to the touch. Diarrhœea is usual. She is quite infantile in her habits. She sleeps badly. Reflex movements not very dull. Is thirsty. Perspiration not very offensive.

History.-Congenital case. The father is a poor miserable-looking creature. There is no other evidence bearing on the case.

CASE 3.-J. C-, male, æt. 11 years, admitted July 16th, 1859. A slim, long-limbed idiot of the lowest class, with curious choreic motions.

Head.-Circumference 19 $\frac{1}{2}$ inches ; mastoid to mastoid 14 inches ; nasal to occipital $12 \frac{1}{2}$ inches; long diameter $6 \frac{1}{2}$ inches, short $5 \frac{1}{4}$ inches. It is long and narrow. Capacity 44:0.

Face.-Peculiarised by its constant contortions, the mouth being opened, shut, and twisted, the eyes squinted, the brows knit, and the whole head rotated in the oddest manner. Skin sallow, and generally moist from the great flow of saliva. There is an expression of happiness when he is talked to and noticed.

Eyes.-Strabismus of left; they wander restlessly, or are fixed steadily; he has a little power of directing them to objects, but, instead of looking directly at them, he looks out of the corners of his eyes, and lifts his chin obliquely at the same time.

Ears, nose, and mouth.-Well formed. Mouth not large, but allowing the saliva to flow in large quantity ; teeth good. He hears and can be made to listen a little; notices music.

Voice.-No power of enunciating. Howls, cries, and laughs, but does not hum a tune.

Body.-Thin and well made. Muscles flabby; organs healthy; pulse 72. Balances himself in the erect posture, the legs being thrust out and crossed, and the arms extended.

Arms.-Long; the right wrist is bent upon the forearm.

Legs.-Thin ; talipes of both feet. He can balance himself on his toes, if held, and has much volitional power over his limbs.

The whole voluntary muscular system appears to suffer from chorea, and the grimaces and spasmodic gesticulations are most odd. He cannot walk or stand alone. If his attention be arrested, the chorea increases, and it ceases during sleep.

Intellectual powers.- $\mathrm{He}$ has a little power of attention, of discrimination between persons and things, and therefore a little mental perception and memory. He has nothing more. Emotions rarely 
excited, joy, anger, and sorrow being decidedly shown. He knows his mother and me. He is dirty at night, but makes a sort of sign during the day. His habits are those of a child of a few months old. He cannot do anything for himself.

General peculiarities.-His meat has to be cut small and placed on the back of his tongue. The chin is then oddly rotated upwards, and the morsel swallowed with difficulty. Is thirsty. He knows his food. His surface is not over sensitive. He rolls his head a good deal. Perspiration rather offensive. Diarrhoea common. Reflex actions well developed.

History.-Father a drunkard; mother has an odd look, and was frightened by her husband when enceinte; brother has lepra on the face. The case is congenital.

Progress.-In twoyears he has gained a little intelligence, knowsmore people, evinces dislikes, can stand alone a little; can play with toys sitting up to a table, but cannot give a toy to any one, if asked to do so.

CLass II.-The majority of idiots belong to this class; and although some, with growth and education, pass into the next, still its members are found of all ages.

Ability to maintain the erect posture, to walk slouchingly, hesitatingly, and ungracefully, to run in a stumbling manner, to use the hand sufficiently to feed with a spoon and to hold a mug, to be roused to attend to simple requests, and to be enabled to become, with care, cleanly in habit, separates these from the profound idiots. And the defective memory, weak physical powers, the want of general thought, and the presence of intense dulness of comprehension, prevent the majority rising into a class where there is sufficient power of attention, mental concentration, memory, and intellectual perception, coupled with increased co-ordinating powers, to enable writing, reading, and mechanical work to be commenced.

The idiot of the second class may have, as all the others, a well-shaped head and face, or the contrary ; a short body, or a tall one, and may have various deformities. Its characteristic ability to walk and stand, and to direct its vision in a greater or less volitional manner, renders its intense dulness, hebetude, and inability to comprehend the simplest terms, very striking.

The growth of the members of this class is usually slow; they are rarely tall, and, as in the first class, disease has great destroying powers, the vital force being weak, and the constitution more irritable than strong.

There is more capacity for expression in the muscles of the face than in the first class, and the saliva and nasal mucus do not so frequently moisten the chin and breast.

The deformities of the mouth, palate, tongue, and lips are seen as in the profound idiots, but the eyes have more power. They are often wandering or fixedly still, as in brown study; nevertheless, there is visual attention to a greater or less degree. 
The eyes are capable of being directed to certain objects by command or by the free will; and although their function is often very ill performed, and all the varieties of congenital affections exist, still they are useful, and can be placed in rapport with the organs of locomotion and with the other special senses. Objects are recognised by some, and colours also.

The ears, often deformed, are sharp of hearing, and listening is rendered more a habit, by instruction. Distinctive powers, as regards harmonious and rude sounds, exist slightly, and music ever pleases.

The voice is imperfect at the best, and coarse, husky stuttering of a few sentences is the extreme gift. Screaming, humming, and singing are to be heard often enough, and laughing as well. The voice is parrot-like in most instances, that is to say, the sounds bear no reference to a mental effort; in others, sentences picked up by their frequent use during certain decided occurrences are used, at one time properly, as regards their application, and at others for talking sake. Talking is rarely commenced by the idiot of any class; he must be spoken to, as a rule.

Mastication and deglutition are tolerably well performed, and the spooning of victuals is easily taught; but cutting them up is rarely attained.

The hands are capable of a few useful movements, but the want of co-ordination in the muscles of the fingers, when in operation, is as evident as that of the muscles of the inferior extremities in walking and running. Any complicated movements are impossible.

The voluntary muscles are under the influence of a very dull will, and the organic are usually irritable, and yet have more tone than in the first class. Habit, constant direction, and a careful diet will enable the sphincters to become under slight control, and some advance in this department of personal cleanliness may be made. The circulation and digestion are frequently languid, or just the reverse; and these conditions do not bear any decided relation to the amount of idiocy.

The skin is generally dull in sensation, spots of it being exquisitely sensitive, and others very wanting in feeling.

Thirst is often extreme, and voracity as well. The senses of taste and smell are frequently horribly perverted, and excrement appears to have great charms.

Automatic movements of all kinds are seen in excess, and as puberty is passed, and even long before, the genitals are pulled about. Onanism is very frequent, and complicates matters greatly.

There is a little memory of things, but not of events ; many cannot recognise their own, and some will pick out a favorite possession. Attention exists in its lowest degree; intellectual perception is hardly in their economy, yet it exists. Comparison, a little power of concentrating the feeble powers, the notion of self-preservation, and the 
ability of expressing a thought or a slight idea, in the most childlike manner, are to be discovered in some which approach the next class. The emotions are easily excited, and the affections also. Dressing and undressing cannot be done; some cannot get into bed, and working on a slate, knowing a few pictures, naming a few animals and letters, are the outside of the accomplishments of this class.

The members of the second class are not "solitaries;" they can enter, in a slight degree, into correspondence by motions, by uncouth gestures, and by sounds with their fellows; they can play at simple games, and they appear to enjoy society. At the same time, they are helpless, and require as much supervision as the profound idiots.

The following cases belong to the second class :

CASE 4.-E. N-, female, æt. 12 years, admitted July 24, 1860. A tall, slim idiot, with a small head, extraordinary automatic movements, very defective vision, but possessing more intelligence than the true idiots, and therefore not "solitary."

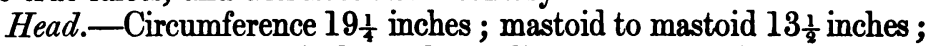
nasal to occipital 11 inches; long diameter $6 \frac{1}{2}$ inches, short 5 inches. Height of forehead $2 \frac{1}{4}$ inches, breadth $3 \frac{3}{4}$ inches. Head small in relation to the body. Capacity 4:1.75.

Face.-Small, thin, and hideous. There is a constant frown; the eyes are on a different line to the eyebrows ; the last are straight and horizontal, the first are oblique and very prominent. The whites are large, and the cornex very small and prominent. The nose is small and red; the mouth large and ever open, showing a ragged set of teeth and a raw-looking tongue. There is usually a grin on the face, with a peering look about the eyes. The saliva and nasal mucus flow in quantity. Vision is imperfect, still it is directed at will; she stures much, and has wandering of the eyes greatly. The eyes are often fixed on space, and the head moved slowly from side to side. The ears are large, but their function, with that of the nose, exists; there is also power of listening and of attending to a command. Arch of palate considerable. Tongue often passed over things, to feel them, instead of the fingers.

Voice.-She can say a few words of abuse, in a parrot-like manner, hums a tune, laughs, and cries.

Body.-Thin and well formed, limbs also. Organs healthy. She can sit up, stand erect, walk, and run a little. The locomotion is very tottering and unsteady. Pulse 72.

Intellectual powers.-Some slight mental perception ; memory very slight; can distinguish between things ; can play with toys a little; knows those about her, and applies her few words properly, sometimes. Emotions :-is passionate.

General peculiarities.-Is very dirty in her habits, smearing excrement about; cannot feed herself, but sits up to table, after a 
fashion. Thirsty. She has automatic movements for days at a time; rolling the head from side to side when reclining, and whirling round like a top when placed on her feet. Sleeps badly, walking about at night in the dark. Has diarrhœa frequently. Perspiration offensive. She frequently strikes her face.

History.-Congenital. Mother weak minded. Has been badly treated.

Progress.-In four months she sat up to table, without any automatic movement, and spooned her food ; moreover, she drank out of her own mug, played with coloured beads, became more tidy and clean, slept better, and subsequently evinced powers of imitation. She has had relapses of the movements, but nine months' training has rendered her lively, useful in fetching things, more independent, clean, and highly imitative. She knows visitors well.

CaSE 5.-J. E-, female, æt. 15, admitted July 7, 1860. A high-shouldered, lame, small-headed idiot, very simia-like.

Head.-Circumference 20 inches; mastoid to mastoid $13 \frac{1}{8}$ inches; nasal to occipital 11 inches; long diameter $6 \frac{3}{4}$ inches, short $5 \frac{1}{4}$ inches. Height of forehead 2 inches, breadth 4 inches. Head small in relation to the face and the large trunk; capacity 43 inches.

Face.-Features irregular, eyes deep set, nose small and flat, lower jaw very large and prominent, chin very prominent. The skin is dusky and furrowed. Expression none, when quiet; but it becomes pleased or fierce, as the case may be. Forehead receding and low.

Eyes.-Strabismus of the right. Vision sharp, and the visual attention slight. Much wandering vision, and fixedness as well.

Ears.-Large; hearing quick and good. Is fond of music.

Sense of smell and taste appear to be normal. No excess of saliva.

Speech.-Exists in a husky, jerking, and rude manner; the words are few, but, simple as they are, they are properly spoken and applied.

Body. - Trunk large, limbs short, contraction of right knee; the left arm is rarely quiet; she is left handed. The walking is bad; she steps short, and moves one ley first. Can run a little, sit up, get in and out of bed; can spoon her food, plays about. Cannot dress herself; but can hold things, and make herself useful. Pulse 60 .

Intellectual powers.- Has slight memory, which is restricted to persons and things of every-day contact. She remembers a few names. Some considerable powers of attention and of mental perception exist. She has ideas and fancies, and a few opinions. She thinks those that sleep are dead, that I shall cure her knee, and she thought a picture of a monkey one " of us." Is very sensitive to external impressions, although the impression is transitory. Has ideas of selfpreservation. Emotions rarely excited; terribly violent and passionate at home; here, placid and good, affectionate and obedient.

General peculiarities. - She has a few automatic movements, sits 
with her head looking over her shoulder, with the eyes fixed upwards, and the chin poked forward and upward. When she moves from this position, the chin is not lowered, and the head is moved from side, just in the favorite manner of supercilious-looking apes. She eats, drinks, and sleeps well ; is clean in her habits, going to the closet herself. Bowels open regularly. Catamenia present. No vice.

History.-Her mother is very silly, and a low type of normal mind.

Progress.-She is a docile obedient girl, is drilled and has fingerlessons, marks a little on a slate, and speaks better.

CAsE 6. - S. A. R - female, æt. 10 years, admitted August 10, 1860. A short, stout-built idiot, with small forehead, large underjaws, and a very vacant expression, except about the eyes.

Head.-Circumference 201 inches; mastoid to mastoid 14- inches; occiput to nasal $12 \frac{1}{2}$ inches ; long diameter 7 inches, short diameter $5 \frac{1}{8}$ inches; height of forehead $1 \frac{1}{8}$ inch, breadth $3 \frac{1}{4}$ inches. The back of the head is developed to the prejudice of the front. Capacity 45.25.

Face.-Expression vacant, placid, and never varying; forehead small; lower jaw large. Eyes well made; she sees well, and can direct her vision to objects, when she is told to do so. Some fixedness of the eyes occasionally. Ears rather large; hears well and listens tolerably ; is fond of music. Nose well made, mouth also ; palatal arch high. Discriminates between scents, and tastes well. No excess of saliva.

Foice.-Husky and jerking; there is some little power of enunciating syllables, but in a defective manner. She knows several words, and says them incorrectly. Cannot sing.

Body and limbs.-Well formed; muscular power strong. She sits up, stands, walks, runs, and jumps. The walking is slouchingly done, and she runs with the hands spread out before her. The defective co-ordination in her locomotion is very evident. Bowels open daily. Pulse 70.

Intellectual powers.-Of a very low order. Memory very scant; perception (of both varieties) very dull. Good idea of self-preservation; some power of comparison; she knows very slightly some of her own things. Cannot be rendered sufficiently attentive to be instructed. Her will is tolerably developed, and she can interest herself with her playfellows. Emotions sluggish; she is goodtempered, obedient, gay.

General peculiarities.-No automatic movements; diarrhœa occasionally. Eats and sleeps well. Cannot dress herself; can spoon her food, but not cut it up. Is full of tricks, rather destructive, plays with toys, and is drilled. Perspiration not offensive; is quite clean in her habits.

History.-Congenital; nothing, however, bearing on the idiocy. (To be continued.) 

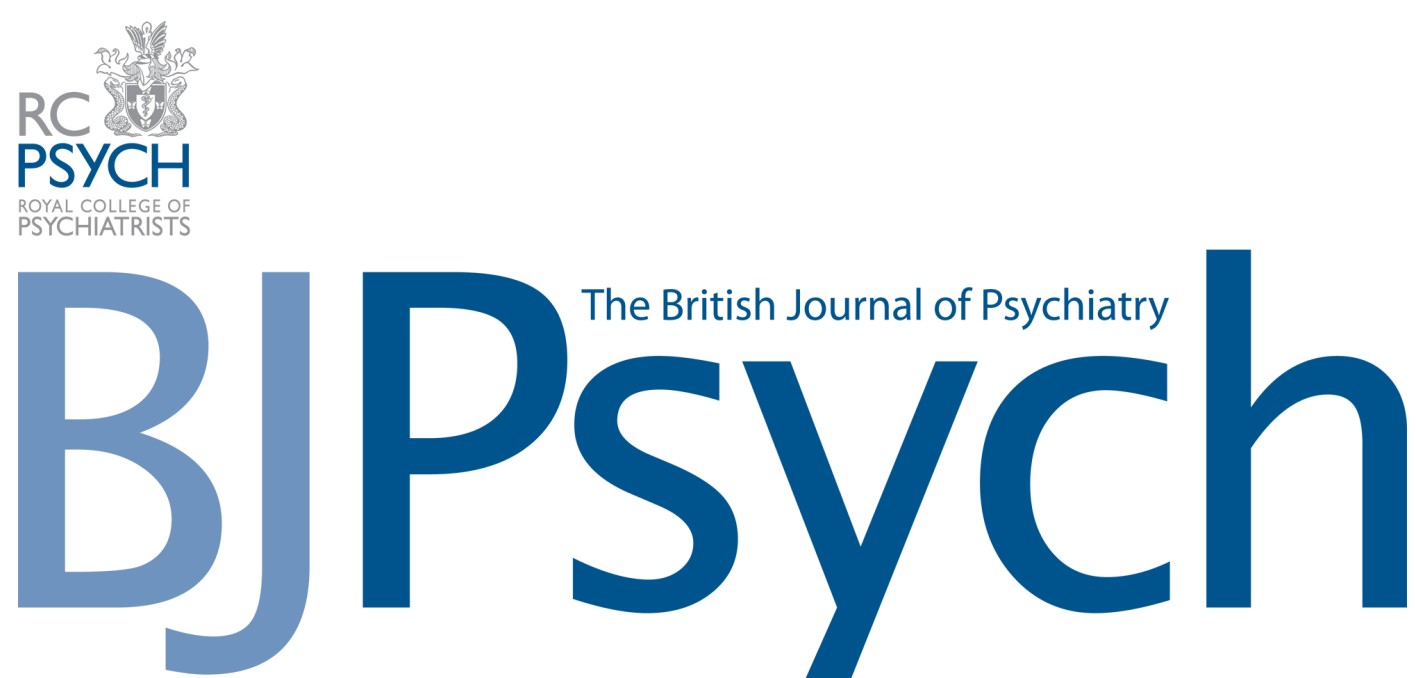

\section{Notes on Idiocy}

P. Martin Duncan

BJP 1861, 7:232-252.

Access the most recent version at DOI: 10.1192/bjp.7.38.232

References This article cites 0 articles, 0 of which you can access for free at: http://bjp.rcpsych.org/content/7/38/232.citation\#BIBL

Reprints/ To obtain reprints or permission to reproduce material from this paper, please write permissions to permissions@rcpsych.ac.uk

You can respond /letters/submit/bjprcpsych;7/38/232

to this article at

Downloaded http://bjp.rcpsych.org/ on April 14, 2017

from Published by The Royal College of Psychiatrists

To subscribe to The British Journal of Psychiatry go to:

http://bjp.rcpsych.org/site/subscriptions/ 